\title{
Dose-related effects of MDMA on psychomotor function and mood before, during, and after a night of sleep loss
}

\author{
Wendy M. Bosker • Kim P. C. Kuypers • Silke Conen • \\ Johannes G. Ramaekers
}

Received: 4 August 2009 / Accepted: 21 December 2009 /Published online: 19 January 2010

(C) The Author(s) 2010. This article is published with open access at Springerlink.com

\begin{abstract}
Introduction 3,4-methylenedioxymethamphetamine (MDMA) is known to improve psychomotor function and mood when measured during daytime. However, MDMA users tend to take this drug at dance parties while staying awake for prolonged periods of time.

Subjects and methods This study was designed to assess dose-related residual effects of MDMA on psychomotor function and mood after a night without sleep. Sixteen recreational MDMA users received single doses of 25, 50, and $100 \mathrm{mg}$ MDMA in a randomized, double-blind, placebo-controlled cross-over study.

Results Results showed that sleep loss significantly impaired psychomotor function. MDMA generally did not affect performance but did improve rapid information processing at the highest dose in the morning after administration. In the evening, MDMA also increased subjective ratings of positive mood at every dose and subjective arousal at the highest dose. These subjective effects were no longer present after a night of sleep loss.

Discussion It is concluded that sleep deprivation impairs psychomotor function and that stimulant effects of MDMA are not sufficient to compensate for this impairment.
\end{abstract}

Keywords MDMA · Ecstasy $\cdot$ Psychomotor $\cdot$ Cognition · Mood $\cdot$ Sleep deprivation

W. M. Bosker $(\bowtie) \cdot$ K. P. C. Kuypers $\cdot$ S. Conen $\cdot$

J. G. Ramaekers

Department of Neuropsychology and Psychopharmacology,

Maastricht University,

Maastricht, The Netherlands

e-mail: Wendy.bosker@maastrichtuniversity.nl

\section{Introduction}

3,4-methylenedioxymethamphetamine (MDMA) is the main psychoactive substance of the party drug ecstasy. Ecstasy is a popular drug: about $0.4 \%$ of the Dutch general population $(40,000$ people) has been described as current user in 2005 (National Drug Monitor 2008) and 9.5 million European adults indicated to have ever used ecstasy, which is $2.8 \%$ of the general population (European Monitoring Centre for Drugs and Drug Addiction 2008). Ecstasy has been described as an entactogen, because of its subjective effect of feeling close to and connected with others. Other drug effects are enhanced visual and auditory perception: colors appear brighter and sounds seem more intense. This is why people generally take ecstasy at dance parties where rhythmic music is being played in combination with colorful lights. Also, the stimulant effects enable people to dance for longer periods of time.

An extensive body of literature showed that ecstasy may produce detrimental effects on cognitive and psychomotor functions. For example, Morgan et al. (2006) found that ecstasy users were impaired on several measures of impulsivity compared to groups of polydrug users and drug-naïve controls. Two meta-analytic reviews demonstrated that ecstasy users performed significantly worse on cognitive tasks measuring learning/memory, attention, executive function, and psychomotor performance compared to non-using control subjects, although effect sizes were medium to small (Kalechstein et al. 2007; Zakzanis et al. 2007). However, a large number of studies have also failed to exclusively link MDMA use to long-term cognitive impairments. Roiser et al. (2007) reported that performance of current ecstasy users, former-ecstasy users, polydrug users, and drug-naïve controls on tests measuring memory, executive function, and impulsivity did not differ 
between groups. Clark et al. (2009) reported no performance difference between ecstasy users and controls on a task that measured impulsivity. Hoshi et al. (2007) and Hanson et al. (2008) concluded that the subtle impairments of memory and impulse control in MDMA users were due to polydrug use rather than ecstasy use alone. Likewise, Lamers et al. (2006) and Jager et al. (2008) concluded that impairments in cognitive and psychomotor function of MDMA users may be attributed to other drugs than MDMA, such as cannabis and amphetamine.

These conflicting findings of MDMA impairing performance in some, but not all, studies have been attributed to methodological problems inherent in cross-sectional designs in abstinent drug users. For example, the fact that most ecstasy users also take other drugs is an important confounder. Thus, the results of the aforementioned studies could be due to the use of other drugs than MDMA. Another related problem is causality: the nature of crosssectional designs does not allow inferences on whether the effects are caused by ecstasy or another factor, e.g., premorbid factors that might make people more vulnerable to use illicit drugs (Morgan 2000).

One way to overcome these problems is to study acute effects of MDMA on cognitive performance in placebocontrolled experimental designs. In such designs, changes in performance can be exclusively linked to the experimental drug. Experimental studies have previously shown that single doses of MDMA impair memory function (Dumont et al. 2008; Kuypers and Ramaekers 2005, 2007; Ramaekers et al. 2009) and attention (Dumont et al. 2008) and improve performance on tasks measuring impulse control (Ramaekers and Kuypers 2006) and psychomotor function (Lamers et al. 2003) when given during the day. The magnitude of impairment on memory and attention increased when MDMA was given during the night to subjects who stayed awake throughout the night. Moreover, stimulating effects of nocturnal doses of MDMA on psychomotor function, vigilance, and sleepiness were very mild or no longer present after a night of sleep loss (Kuypers et al. 2007, 2008). In the latter studies, repeated doses of 75 and $50 \mathrm{mg}$ MDMA were administered to subjects, which resulted in psychomotor impairment additive to impairment produced by sleep loss. However, MDMA also produced some mild stimulatory effects; it reduced subjective feelings of sleepiness and mildly increased vigilance performance in the morning.

At present, it is not clear at which MDMA dose or serum concentration residual impairments start to emerge. Residual effects are limited to the time window in which the drug is still present in blood, but at low concentrations. The objectives of the present study were to establish the residual effects of MDMA on cognitive performance early in the morning as a function of MDMA dose. Subjects were treated on four separate occasions with evening doses of $0,25,50$, and $100 \mathrm{mg}$. Because identical MDMA doses can lead to different MDMA blood concentrations, it is important to study MDMA effects or it's interaction with sleep deprivation as a function of MDMA concentrations rather than dose. We decided to include a broad range of (low) nocturnal doses in order to be able to measure residual MDMA effects at very low concentrations in the morning. This wide range of residual blood concentrations will help determine the MDMA concentration threshold at which residual performance effects will still be present. Performance was tested in the evening, in the middle of the night, and in the morning after a night of sleep loss.

\section{Subjects and methods}

\section{Subjects}

Eight males and eight females participated in this study. Their mean (SE) age was $22.0(0.41)$ years, and their mean (SE) lifetime MDMA use was 27.0 (8.4) times. Subjects were recruited by advertisements at Maastricht University and were paid upon completion of the study. Before enrollment, all subjects were screened by means of a telephone interview to determine whether they qualified for the study. The inclusion criteria were experience with MDMA, i.e., at least one time in the last year; free from psychotropic medication; good physical health as determined by a medical examination; absence of any major medical, endocrine, and neurological condition; body mass index between 18 and 28; and written informed consent. The exclusion criteria were history of drug abuse or addiction as assessed by means of a medical questionnaire by the physician at the medical checkup; pregnancy or lactation; cardiovascular abnormalities on electrocardiogram; excessive drinking, i.e., more than 20 alcoholic consumptions a week; hypertension, i.e., systolic blood pressure over $170 \mathrm{mmHg}$ or diastolic blood pressure over $100 \mathrm{mmHg}$; and history of or current psychiatric disorder. If subjects met the inclusion criteria, they received a medical history and a drug questionnaire to get a more precise view on their health and drug use. Finally, subjects underwent a medical examination and took part in a training session to get familiar with the tests.

This study was conducted according to the code of ethics on human experimentation established by the declaration of Helsinki (1964) and amended in Seoul (2008). Approval for the study was obtained from the Medical Ethics committee of the Academic Hospital of Maastricht and Maastricht University. A permit for obtaining, storing, and administering MDMA was obtained from the Dutch drug enforcement administration. 
Study design

The study was conducted according to a double-blind, placebo-controlled, randomized, four-way, cross-over design. Treatments consisted of single doses of placebo, 25, 50, and $100 \mathrm{mg}$ MDMA. Treatment orders were balanced over subjects and treatment periods. Placebo and MDMA were administered orally in identically appearing formulations. MDMA was dissolved in $25 \mathrm{~mL}$ bitter orange peel syrup, and placebo consisted of only the bitter orange peel syrup. The syrup was mixed with $200 \mathrm{~mL}$ juice before it was given to the subjects. The wash-out period between treatments was at least 1 week.

\section{Procedure}

Subjects were asked to refrain from any drugs 1 week before the medical examination until 2 weeks after study completion. Subjects were not allowed to drink alcohol and caffeine or smoke tobacco during a 24-h period prior to testing. Subjects were always tested for alcohol and drugs, i.e., tetrahydrocannabinol, opiates, amphetamine/ecstasy, benzodiazepines, cocaine, and methamphetamine/ecstasy, respectively, in breath and urine upon arrival (4:30 p.m.) at the laboratory on test days. At 5:00 p.m. subjects received a light, standard dinner, and at 5:15 p.m., MDMA or placebo was administered. Performance was assessed in the evening, the middle of the night, and in the morning after a night of sleep loss. The timeline for performance testing, questionnaires, and blood draws are displayed in Fig. 1. Subjects watched television or movies, played games, read a book or magazine, or used the internet in between testing episodes during a test night. An additional blood sample was drawn 1 week after each testing day to monitor renal and liver function. A test day ended at 9:00 a.m. the next morning, at which time, subjects were driven home.

\section{Psychomotor assessment}

The stop signal task required subjects to make quick key responses to visually presented go signals and to inhibit their response when a visual stop signal was suddenly presented. The go signals were four $1.5 \mathrm{~cm}$ letters (A, B, C, and $\mathrm{D}$ ) presented one at a time in the center of a computer screen. Subjects were required to respond to each letter as quickly as possible by pressing one of two response buttons. One button was pressed to indicate that $\mathrm{A}$ or $\mathrm{C}$ appeared and the other to indicate B or D. Letters were displayed for $500 \mathrm{~ms}$, and the computer screen was blank for $1.5 \mathrm{~s}$ inter-stimulus interval. This provided a period of $2 \mathrm{~s}$ in which the subject could respond to a letter. A single test consisted of 176 trials in which each of the four-letter stimuli was presented equally often. A stop signal occurred in 48 trials during a test. The stop signal consisted of a visual cue, i.e., *, that appeared in one of the four corners of the screen. Stop signals were presented 12 times at each of the four delays after the onset of a letter: 50, 150, 250, and $350 \mathrm{~ms}$. Trials always began with a $500-\mathrm{ms}$ preparation interval in which a fixation point appeared in the center of the screen. The task lasted about $10 \mathrm{~min}$. Dependent variables were the proportion of commission errors on stop trials and the reaction times (RT) on go as well as stop trials, i.e., stop RT. Stop RT represents the estimated mean time required to inhibit a response and is a measure of impulsivity (Fillmore et al. 2002; Ramaekers and Kuypers 2006).

The rapid information-processing task is a self-paced interactive working memory task that assessed subjects' information-processing capacity. A pseudo-random sequence of 250 digits (1-8) was presented in the center of the screen. The digits were presented one at a time for $67 \mathrm{~ms}$ with an initial inter-stimulus-interval (ISI) of $600 \mathrm{~ms}$. Subjects had to press a button when they saw the third digit of a three-digit sequence (triad) that was comprised of even (e.g., 6, 2, and 4) and odd (e.g., 5, 1, and 7) digits. The entire 250-digit sequence contained 11 even-digit triads and ten odd-digit triads. Each correct response speeded up the presentation rate by decreasing the ISI with $33 \mathrm{~ms}$, and each false response slowed it down with $33 \mathrm{~ms}$. Task duration was $5 \mathrm{~min}$; the 250-digit sequence was presented in a repeated loop. The initial presentation rate of the test was 90 digits per minute, and the dependent variable was the average number of digits per minute presented in the test (Fillmore et al. 2005).

The divided attention task assessed the ability to divide attention between two tasks performed simultaneously. The

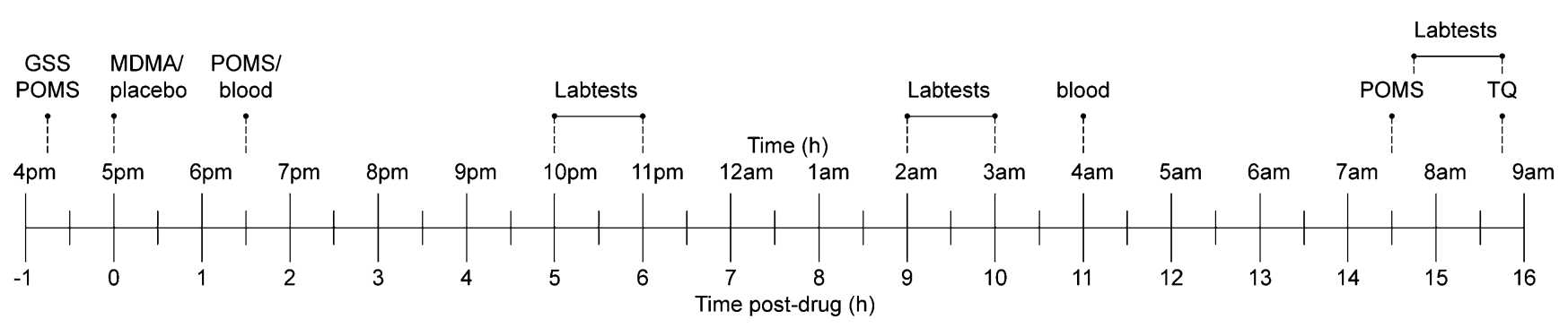

Fig. 1 Timeline for blood samples, questionnaires, and laboratory tests relative to drug administration. GSS Groninger sleep scale, POMS profile of mood states, $T Q$ treatment questionnaire 
primary task required the use of a joystick to continuously null the horizontal movement of a cursor from the center of a display. The cursor traveled in both directions with irregular velocity, but on average, $50 \%$ of what the subject could just control. The dependent measures of this subtask were control losses and tracking error, which was measured by the absolute distance (millimeters) between the cursor's position and the center. The secondary task involved monitoring 24 single-digit numbers (0-9) that were arranged in the four corners of the display. The numbers changed asynchronously every $5 \mathrm{~s}$. The requirement was to react as rapidly as possible by lifting the foot from a pedal every time a target, i.e., the number 2, appeared. Average reaction time to targets was recorded as the dependent measure (Moskowitz 1973).

The psychomotor vigilance task assessed the reaction time in response to a visual stimulus. The visual stimulus was a counter in the center of a computer screen that ran in $1 \mathrm{~min}$ from 0 to 60 with a fixed inter-stimulus interval of $1 \mathrm{~ms}$. The counter started at random intervals between 2 and $10 \mathrm{~s}$, and the subject had to react to the onset of the counter as quickly as possible by pressing a response button. Duration of the task was 10 min. This task has often been used to assess the impact of sleep loss on performance (Loh et al. 2004).

\section{Subjective measures}

The Groninger sleep scale assessed sleep quality and quantity (hours of sleep). It consisted of 15 dichotomous questions about sleep complaints and an open question concerning the duration of sleep (Mulder-Hajonides van der Meulen et al. 1980). The quality score ranged from 0 (best quality of sleep) to 15 (worst quality of sleep).

The profile of mood states is a self-assessment mood questionnaire with 72 five-point Likert scale items, representing eight mood states, i.e., anxiety, depression, anger, vigor, fatigue, confusion, friendliness, and elation. Three composite scales were derived, i.e., arousal ((anxiety + vigor) - (fatigue + confusion)), positive mood (elation-depression), and a total score ((anxiety+depression + anger+fatigue $)$ - vigor), which is a measure of malaise. The subject had to indicate to what extent these items were representing his/her mood (de Wit et al. 2002).

\section{Pharmacokinetic assessment}

Blood samples $(8 \mathrm{~mL})$ were collected two times throughout a testing day/night, i.e., at 1.5 and $11 \mathrm{~h}$ post-drug. MDMA and 3,4-methylenedioxyamphetamine (MDA) concentrations were determined afterwards in serum. The blood sample was centrifuged immediately, and the resulting serum was frozen at $-20^{\circ} \mathrm{C}$ until analyses for pharmacokinetic assessments.
Statistical analyses

All statistical analyses were conducted by means of SPSS 16.0 for Mac. All data were entered in the general linear model (GLM) repeated measures analysis of variance (ANOVA) procedures with MDMA (four levels) and hours of sleep loss (three levels) as main within-subject factors. If the sphericity assumption was violated, the GreenhouseGeisser correction was used. In case of an overall effect of MDMA or an interaction effect between MDMA and sleep loss, separate drug-placebo contrast analyses were conducted for each MDMA dose. In case of the profile of mood states, difference scores between post-drug and the pre-drug score entered the statistical analysis.

\section{Results}

Psychomotor assessment

Mean (SE) performance scores obtained from psychomotor tests are displayed in Table 1 along with $p$ values associated with GLM ANOVA.

MDMA did not affect performance in any of the psychomotor tasks. Sleep loss impaired performance on a range of tasks. It increased RT $\left(F_{2,30}=6.415, p=0.005\right)$ and stop RT $\left(F_{2,30}=3.685, p=0.037\right)$ in the stop signal task, processing speed in the rapid information-processing task $\left(F_{2,30}=7.896, p=0.002\right)$, and RT in the psychomotor vigilance task $\left(F_{2,30}=16.598, p=0.000\right)$. Sleep loss also increased control losses $\left(F_{1.345,20.171}=14.272, p=0.001\right)$, tracking error $\left(F_{2,30}=16.449, p=0.000\right)$, and RT $\left(F_{2,30}=\right.$ $35.538, p=0.000$ ) in the divided attention task.

The interaction between MDMA and sleep loss was significant for processing speed $\left(F_{6,90}=2.616, p=0.022\right)$ in the rapid information-processing task. Simple drug-placebo contrasts showed that this interaction effect was attributable to MDMA $100 \mathrm{mg}(p=0.001)$. Performance during the placebo condition worsened during the night, while in the 100-mg MDMA condition, subjects' performance remained stable throughout the night and slightly improved in the morning (see Fig. 2).

\section{Subjective measures}

There were no significant differences in sleep quality and quantity between any of the MDMA conditions as measured by Groninger sleep scale. Subjects' mean (SE) quality of sleep and hours of sleep were $2.22(0.36)$ and $8.5(0.24)$, respectively.

ANOVA of the profile of mood states showed a significant interaction between MDMA and sleep loss on the arousal $\left(F_{3,45}=4.294, p=0.010\right)$ and positive mood scale 
Table 1 Mean (SE) of the cognitive and psychomotor tests for the treatment conditions and measuring times

\begin{tabular}{|c|c|c|c|c|c|c|c|c|}
\hline \multirow[t]{2}{*}{ Test } & \multirow[t]{2}{*}{ Measure } & \multirow[t]{2}{*}{ Placebo } & \multirow{2}{*}{$\begin{array}{l}25 \mathrm{mg} \\
\text { MDMA }\end{array}$} & \multirow{2}{*}{$\begin{array}{l}\text { 50mg } \\
\text { MDMA }\end{array}$} & \multirow{2}{*}{$\begin{array}{l}\text { 100mg } \\
\text { MDMA }\end{array}$} & \multicolumn{3}{|l|}{ ANOVA } \\
\hline & & & & & & $\begin{array}{l}\text { Sleep } \\
\text { deprivation }\end{array}$ & MDMA & $\begin{array}{l}\text { MDMA × sleep } \\
\text { deprivation }\end{array}$ \\
\hline \multicolumn{9}{|l|}{ Stop signal task } \\
\hline \multirow[t]{3}{*}{ Commission errors $(\mathrm{N})$} & 1 & $4.8(0.7)$ & $4.5(0.6)$ & $5.1(0.7)$ & $5.3(0.8)$ & & & \\
\hline & 2 & $5.5(0.8)$ & $3.0(0.6)$ & $4.5(0.7)$ & $4.8(0.7)$ & - & - & - \\
\hline & 3 & $5.6(0.7)$ & $5.6(0.6)$ & $4.9(0.6)$ & $5.1(0.7)$ & & & \\
\hline \multirow[t]{3}{*}{ RT go (ms) } & 1 & $543(36)$ & $540(23)$ & $528(25)$ & $523(23)$ & & & \\
\hline & 2 & $551(35)$ & $595(30)$ & $552(27)$ & $542(28)$ & 0.005 & - & - \\
\hline & 3 & $555(34)$ & $585(29)$ & $562(26)$ & $578(30)$ & & & \\
\hline \multirow[t]{3}{*}{ Stop RT (ms) } & 1 & $276(20)$ & $271(11)$ & $292(23)$ & $315(33)$ & & & \\
\hline & 2 & $327(22)$ & $290(11)$ & $279(18)$ & $299(22)$ & 0.037 & - & - \\
\hline & 3 & $309(25)$ & $297(16)$ & $320(33)$ & $334(23)$ & & & \\
\hline \multicolumn{9}{|l|}{ Rapid information processing } \\
\hline \multirow[t]{3}{*}{ Processing speed (N/min) } & 1 & $529.0(18.9)$ & $525.2(20.3)$ & $506.0(22.2)$ & $522.1(20.6)$ & & & \\
\hline & 2 & $519.4(20.3)$ & $511.8(20.3)$ & $496.1(14.2)$ & $517.3(18.2)$ & 0.002 & - & 0.022 \\
\hline & 3 & $468.0(18.3)$ & $462.9(22.1)$ & $479.9(17.1)$ & $526.4(20.6)$ & & & \\
\hline \multicolumn{9}{|l|}{ Divided attention task } \\
\hline \multirow[t]{3}{*}{ Control loss $(\mathrm{N})$} & 1 & $1.9(0.7)$ & $1.8(0.5$ & $2.9(1.3)$ & $1.6(0.5)$ & & & \\
\hline & 2 & $12.6(8.9)$ & $14.4(6.2)$ & $5.6(1.8)$ & $6.1(2.9)$ & 0.001 & - & - \\
\hline & 3 & $48.4(12.3)$ & $33.4(7.2)$ & $47.9(14.3)$ & $24.7(5.7)$ & & & \\
\hline \multirow[t]{3}{*}{ Tracking error (mm) } & 1 & $15.2(1.1)$ & $15.7(1.2)$ & $15.2(1.0)$ & $14.1(1.2)$ & & & \\
\hline & 2 & $15.9(1.3)$ & $17.3(1.1)$ & $16.1(1.2)$ & $15.5(1.3)$ & 0.000 & - & - \\
\hline & 3 & $19.3(0.9)$ & $19.7(0.9)$ & $18.0(0.8)$ & $18.5(1.0)$ & & & \\
\hline \multirow[t]{3}{*}{$\mathrm{RT}(\mathrm{ms})$} & 1 & $1,822(63)$ & $1,853(79)$ & $1,885(74)$ & $1,920(70)$ & 0.000 & - & - \\
\hline & 2 & $2,046(89)$ & $2,013(79)$ & $2,017(89)$ & $1,973(74)$ & & & \\
\hline & 3 & $2,180(65)$ & $2,189(66)$ & $2,246(69)$ & $2,285(73)$ & & & \\
\hline \multicolumn{9}{|l|}{ Psychomotor vigilance task } \\
\hline \multirow[t]{3}{*}{$\mathrm{RT}(\mathrm{ms})$} & 1 & $289(8)$ & $286(8)$ & $295(15)$ & $301(13)$ & & & \\
\hline & 2 & $384(47)$ & $493(108)$ & $456(76)$ & $349(26)$ & 0.000 & - & - \\
\hline & 3 & $464(29)$ & $463(45)$ & $544(49)$ & $515(38)$ & & & \\
\hline
\end{tabular}

Significance indicated by $p$ value

$\left(F_{3,45}=9.526, p=0.000\right)$. Simple drug-placebo contrasts indicated that MDMA $100 \mathrm{mg}$ increased arousal $(p=0.012)$ in the evening but not in the morning, as compared to placebo. Drug-placebo contrasts also showed that all MDMA doses $(p<0.046)$ increased positive mood in the evening after drug intake but not in the morning. Mean (SE) arousal and positive mood ratings during treatment are given in Figs. 3 and 4, respectively.

\section{Pharmacokinetic assessment}

Pharmacokinetic analysis in serum revealed mean (SE) MDMA concentrations of 25.8 (3.3), 63.9 (6.4), and 157.2 (9.5) $\mathrm{ng} / \mathrm{mL}$ at $1.5 \mathrm{~h}$ after administration of a $25-, 50-$, and 100 -mg dose, respectively. At $11.5 \mathrm{~h}$ post-drug, these concentrations were 14.2 (2.7), 34.0 (3.9), and 84.3

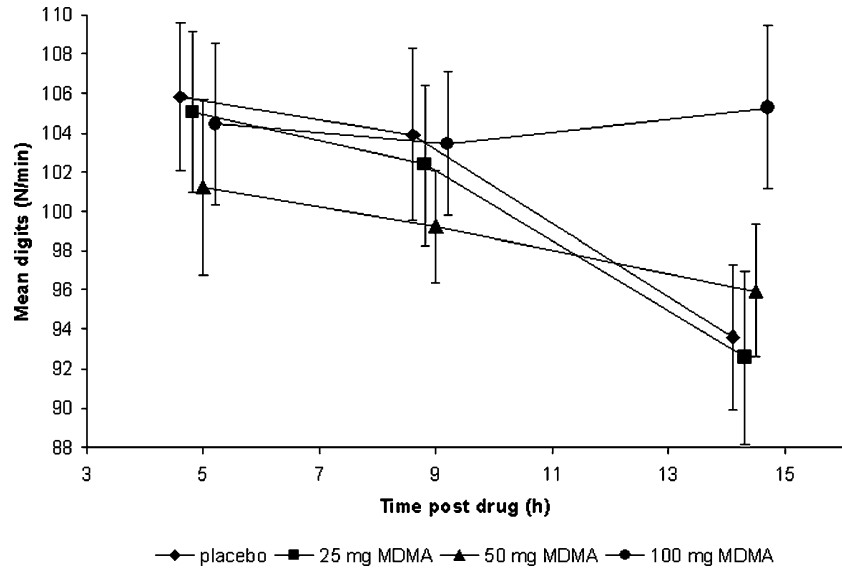

Fig. 2 Mean (SE) performance on the rapid information-processing task in every treatment condition as a function of time after drug administration 


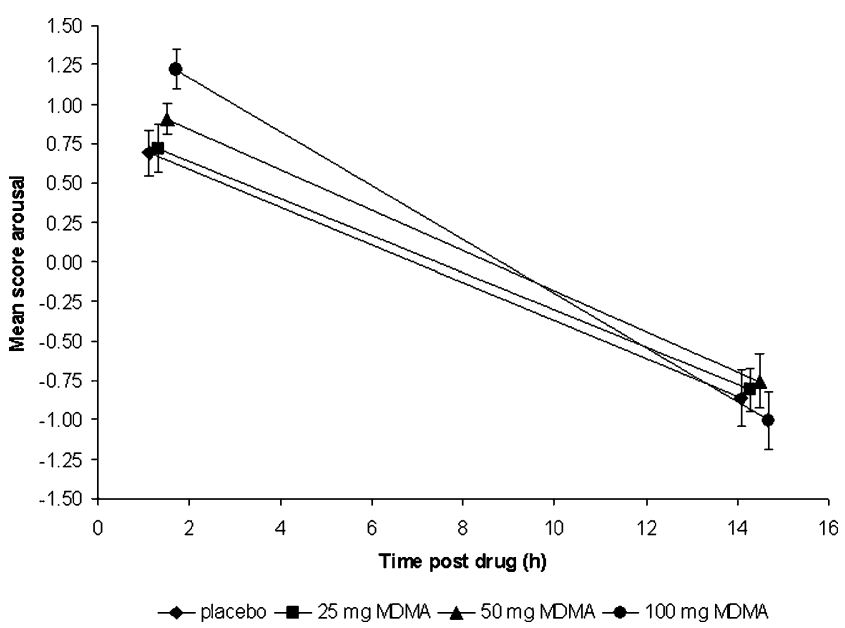

Fig. 3 Mean (SE) score on profile of mood states arousal scale in every treatment condition as a function of time after drug administration

(6.7) $\mathrm{ng} / \mathrm{mL}$, respectively. MDA concentrations were too low to detect.

\section{Discussion}

The present study showed significant impairing effects of sleep loss on various psychomotor measures. Performance deteriorated without exception on all tasks as the hours of sleep loss increased. RT in the stop signal, divided attention, and psychomotor vigilance task as well as processing speed in the rapid information-processing task slowed down over time. Tracking error increased in the divided attention task, which indicates that subjects were unable to allocate sufficient cognitive resources to perform the primary tracking task at a normal, placebo level, despite a general slowing of RT in the secondary task. The number of control losses increased dramatically in the morning after sleep deprivation. Together, this shows that sleep deprivation produced gross impairment of cognitive and psychomotor functions. Similar findings have previously been reported by Kuypers et al. (2007, 2008) and Dawson and Reid (1997). The latter even demonstrated that performance decrements for each hour of wakefulness between 10 and $26 \mathrm{~h}$ were equivalent to a performance decrement observed with a $0.004 \%$ rise in blood alcohol concentration. According to their model, performance of subjects in the present study after 17-24 h of sustained wakefulness would have decreased to a level equivalent to the performance impairment observed at a blood alcohol concentration of roughly $0.05-0.10 \%$.

This study showed no main effects of MDMA on performance, neither in the evening after drug administration nor throughout the night. This contrasts somewhat with findings of previous studies who reported neutral or even stimulating effects on psychomotor function after single doses of MDMA, particularly around $T_{\max }$ (Kuypers et al. 2007; Lamers et al. 2003; Ramaekers and Kuypers 2006; Ramaekers et al. 2006). It should be noted however that the MDMA doses/concentrations in the present study were relatively low compared to previous studies. This was particularly true for MDMA concentrations early in the morning. In the present study, the mean MDMA concentration in the 100-mg MDMA condition was $84.3 \mathrm{ng} / \mathrm{mL}$ at $11.5 \mathrm{~h}$ post-dosing. This concentration was about 2.5 times lower than the concentration reported in a previous study assessing the effect of repeated doses of MDMA on psychomotor function after a night of sleep loss (Kuypers et al. 2007, 2008).

The only significant interaction between MDMA and sleep loss was caused by the highest dose of MDMA in the present study. Relative to placebo, performance in the rapid information-processing task slightly improved 14-15 h after MDMA $100 \mathrm{mg}$, after a full night of sleep loss. This interaction confirms some of the mild stimulatory characteristics that have been reported before when measuring MDMA effects at $T_{\max }$ (Kuypers et al. 2006; Ramaekers et al. 2006). In general, acute drug studies have shown that MDMA effects subside over time and normalize after about $6 \mathrm{~h}$ after administration when taken during the day (HernándezLópez et al. 2002; Dumont et al. 2009). However, MDMA effects on cognition may last longer or become more noticeable when taken during the night or after a night without sleep, because they may add to or even interact with the detrimental effects of sleep loss on cognition. Kuypers et al. (2007) demonstrated that nocturnal doses of MDMA significant increased vigilance and decreased sleepiness in the morning after a night of sleep loss. These results confirm the residual, mild, stimulatory effects of MDMA on psychomotor function that were measured in the present study after a night of sleep loss. These data seem to indicate that mild

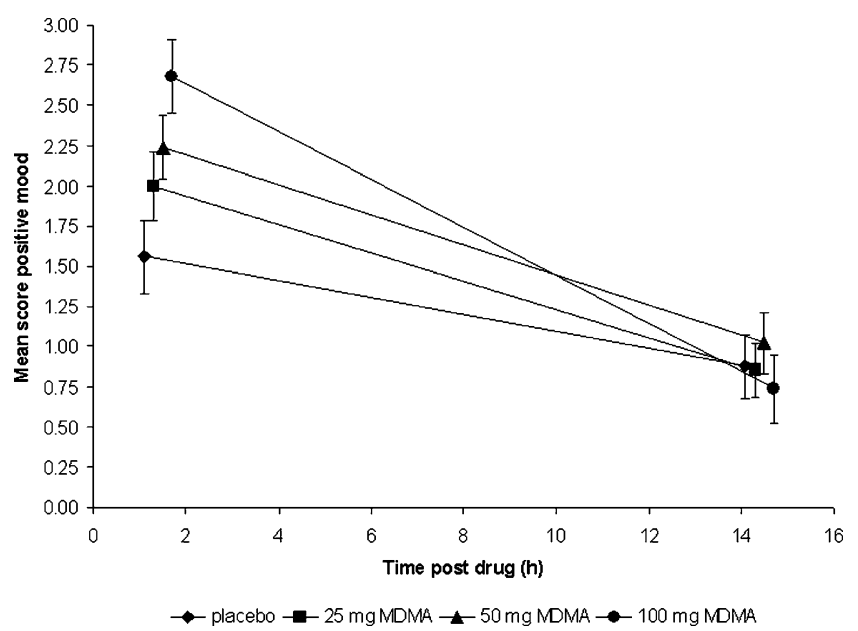

Fig. 4 Mean (SE) score on profile of mood states positive mood scale in every treatment condition as a function of time after drug administration 
stimulatory effects of MDMA may compensate somewhat for the impairing effects of sleep loss on performance. However, this effect of MDMA was very mild and only apparent in a single performance task. Overall, MDMA did not compensate for the detrimental effects of sleep loss on performance. This conclusion is in line with work of others who also showed that stimulant effects of MDMA are generally mild and not sufficient to counteract the impairing effects of other sources such as alcohol (Dumont et al. 2008; Kuypers et al. 2006).

The profile of mood states rating scales confirmed that subjects actively experienced an MDMA effect even after the lowest dose of $25 \mathrm{mg}$. Ratings of positive mood were significantly elevated after all MDMA doses between 1 and $2 \mathrm{~h}$ after dosing. Likewise, feelings of arousal also increased at $T_{\max }$, albeit only after the highest dose. These positive feelings however did not last through the night. When rated in the morning mood and arousal were considerable lower as compared to the evening before, due to sleep loss, and not different from placebo. It again shows that residual concentrations of MDMA or stimulatory effects of MDMA on mood and arousal cannot compensate for decrements in subjective mood and arousal as a result of fatigue.

In summary, it can be concluded that sleep deprivation has a major impairing effect on cognitive and psychomotor performance. Low doses of MDMA generally failed to affect performance but produced some stimulatory effect on rapid information processing at the highest dose. MDMA increased ratings of positive mood and alertness. However, the stimulatory effects of MDMA were only mild and never sufficient to overcome decrements in performance, mood, or arousal due to sleep loss.

\begin{abstract}
Acknowledgement This work was conducted as part of the Driving under the influence of drugs, alcohol, and medicines (DRUID) research consortium funded by European Union grant TREN-05FP6TR-S07.61320-518404-DRUID. This report reflects only the author's view. The European Community is not liable for any use that may be made of the information contained therein.
\end{abstract}

Open Access This article is distributed under the terms of the Creative Commons Attribution Noncommercial License which permits any noncommercial use, distribution, and reproduction in any medium, provided the original author(s) and source are credited.

\section{References}

Clark L, Roiser JP, Robbins TW, Sahakian BJ (2009) Disrupted 'reflection' impulsivity in cannabis users but not current or former ecstasy users. J Psychopharmacol 23:14-22

Dawson D, Reid K (1997) Fatigue, alcohol and performance impairment. Nature 388:235

de Wit H, Enggasser JL, Richards JB (2002) Acute administration of d-amphetamine decreases impulsivity in healthy volunteers. Neuropsychopharmacology 27:813-825
Dumont GJ, Wezenberg E, Valkenberg MM, de Jong CA, Buitelaar JK, van Gerven JM, Verkes RJ (2008) Acute neuropsychological effects of MDMA and ethanol (co-)administration in healthy volunteers. Psychopharmacology (Berl) 197:465-474

Dumont GJ, Schoemaker R, Touw D, Sweep F, Buitelaar J, van Gerven J, Verkes R (2009) Acute psychomotor effects of MDMA and ethanol (co-) administration over time in healthy volunteers. J Psychopharmacol doi: 10.1177/0269881108099214

European Monitoring Centre for Drugs and Drug Addiction (2008) Annual report 2008: the state of the drugs problem in Europe. Office for official publications of the European Communities, Luxembourg

Fillmore MT, Rush CR, Hays L (2002) Acute effects of oral cocaine on inhibitory control of behavior in humans. Drug Alcohol Depend 67:157-167

Fillmore MT, Kelly TH, Martin CA (2005) Effects of d-amphetamine in human models of information processing and inhibitory control. Drug Alcohol Depend 77:151-159

Hanson KL, Luciana M, Sullwold K (2008) Reward-related decisionmaking deficits and elevated impulsivity among MDMA and other drug users. Drug Alcohol Depend 96:99-110

Hernández-López C, Farré M, Roset PN, Menoyo E, Pizarro N, Ortuño J, Torrens M, Camí J, de la Torre R (2002) 3, 4methylenedioxymethamphetamine (ecstasy) and alcohol interactions in humans: psychomotor performance, subjective effects, and pharmacokinetics. J Pharmacol Exp Ther 26:157-165

Hoshi R, Mullins K, Boundy C, Brignell C, Piccini P, Curran HV (2007) Neurocognitive function in current and ex-users of ecstasy in comparison to both matched polydrug-using controls and drug-naive controls. Psychopharmacology (Berl) 194:371-379

Jager G, de Win MM, van der Tweel I, Schilt T, Kahn RS, van den Brink W, van Ree JM, Ramsey NF (2008) Assessment of cognitive brain function in ecstasy users and contributions of other drugs of abuse: results from an FMRI study. Neuropsychopharmacology 33:247258

Kalechstein AD, De La Garza R 2nd, Mahoney JJ 3rd, Fantegrossi WE, Newton TF (2007) MDMA use and neurocognition: a metaanalytic review. Psychopharmacology 189:531-537

Kuypers KP, Ramaekers JG (2005) Transient memory impairment after acute dose of $75 \mathrm{mg}$ 3.4-Methylene-dioxymethamphetamine. J Psychopharmacol 19:633-639

Kuypers KP, Ramaekers JG (2007) Acute dose of MDMA (75 mg) impairs spatial memory for location but leaves contextual processing of visuospatial information unaffected. Psychopharmacology (Berl) 189:557-563

Kuypers KP, Samyn N, Ramaekers JG (2006) MDMA and alcohol effects, combined and alone, on objective and subjective measures of actual driving performance and psychomotor function. Psychopharmacology (Berl) 187:467-475

Kuypers KP, Wingen M, Samyn N, Limbert N, Ramaekers JG (2007) Acute effects of nocturnal doses of MDMA on measures of impulsivity and psychomotor performance throughout the night. Psychopharmacology (Berl) 192:111-119

Kuypers KP, Wingen M, Ramaekers JG (2008) Memory and mood during the night and in the morning after repeated evening doses of MDMA. J Psychopharmacol 22:895-903

Lamers CT, Ramaekers JG, Muntjewerff ND, Sikkema KL, Samyn N, Read NL, Brookhuis KA, Riedel WJ (2003) Dissociable effects of a single dose of ecstasy (MDMA) on psychomotor skills and attentional performance. J Psychopharmacol 17:379-387

Lamers CT, Bechara A, Rizzo M, Ramaekers JG (2006) Cognitive function and mood in MDMA/THC users, THC users and non-drug using controls. J Psychopharmacol 20:302-311

Loh S, Lamond N, Dorrian J, Roach G, Dawson D (2004) The validity of psychomotor vigilance tasks of less than 10-minute duration. Behav Res Methods Instrum Comput 36:339-346 
Morgan MJ (2000) Ecstasy (MDMA): a review of its possible persistent psychological effects. Psychopharmacology (Berl) $152: 230-248$

Morgan MJ, Impallomeni LC, Pirona A, Rogers RD (2006) Elevated impulsivity and impaired decision-making in abstinent ecstasy (MDMA) users compared to polydrug and drug-naive controls. Neuropsychopharmacology 31:1562-1573

Moskowitz H (1973) Laboratory studies of the effects of alcohol on some variables related to driving. J Safety Res 5:185-199

Mulder-Hajonides van der Meulen WREH, Wijnberg JR, Hollanders JJ, DeDiana I, Hoofdakker R (1980) Measurement of subjective sleep quality. Fifth European Congress on Sleep Research, Amsterdam

National Drug Monitor (2008) Annual report 2007. Ladenius Communicatie BV, Houten

Ramaekers JG, Kuypers KP (2006) Acute effects of 3, 4methylenedioxymethamphetamine (MDMA) on behavioral measures of impulsivity: alone and in combination with alcohol. Neuropsychopharmacology 31:1048-1055

Ramaekers JG, Kuypers KP, Samyn N (2006) Stimulant effects of 3, 4-methylenedioxymethamphetamine (MDMA) $75 \mathrm{mg}$ and methylphenidate $20 \mathrm{mg}$ on actual driving during intoxication and withdrawal. Addiction 101:1614-1621

Ramaekers JG, Kuypers KP, Wingen M, Heinecke A, Formisano E (2009) Involvement of inferior parietal lobules in prospective memory impairment during acute MDMA (ecstasy) intoxication: an eventrelated fMRI study. Neuropsychopharmacology 34:1641-1648

Roiser JP, Rogers RD, Sahakian BJ (2007) Neuropsychological function in ecstasy users: a study controlling for polydrug use. Psychopharmacology (Berl) 189:505-516

Zakzanis KK, Campbell Z, Jovanovski D (2007) The neuropsychology of ecstasy (MDMA) use: a quantitative review. Hum Psychopharmacol 22:427-435 